\title{
Psychological approach to the rehabilitation of the spinal cord injured: the contribution of relaxation techniques
}

\author{
M L Curcoll \\ Clinical Psychologist, Institut Guttmann, Garcilaso, 57, 08027-Barcelona, Spain.
}

We analyse the benefit of learning relaxation techniques as an essential coping strategy in the behavioural medicine field. This has proved useful as a part of the newly spinal cord injured rehabilitation treatment or concerning later problems if there is readmission.

We report the changes we have made in the relaxation standard methods to be used in spinal cord injured patients as well as the timing in the rehabilitation process when these techniques were applied.

Key words: spinal cord injury; relaxation techniques; psychological management; rehabilitation.

\section{Introduction}

The relaxation response has physiological effects opposite in nature to those induced by psychological stress. The thoroughly relaxed subject characteristically shows decreased sympathetic responses and increased parasympathetic activity. ${ }^{1}$

In the early $30 \mathrm{~s}$, progressive relaxation, developed by Jacobson, ${ }^{2}$ and autogenic training, developed by Schultz, ${ }^{3}$ were important precursors of the relaxation treatment applied to a considerable range of disorders, many of them stress related.

In the $60 \mathrm{~s}$, muscle relaxation treatment combined with myoelectric control and biofeedback; and in the 70s myoelectric feedback gained a solid following by clinical scientists in the physical rehabilitation field. ${ }^{4}$

At the same time new researches on stress led to emphasising the importance of the cognitive activity and coping strategies in the management of stressful live events. ${ }^{5}$

At present relaxation training has become one of the essential coping techniques in the behavioural medicine field ${ }^{6}$ often in conjunction with biofeedback and/or cognitive training. ${ }^{7}$

Knowledge of the immediate psychological consequences of spinal cord injury is incomplete. Nevertheless many authors have described the psychological disruption caused by the abrupt loss of sensation over part of the body. Hospitalisation and the required separation from family and loved ones in order to get specialised care, are usually other frightening situations. ${ }^{8}$ Das recommends an increase in stimulation over those areas of the body in which sensation remains; and increase in the stimulation of other sensory modalities, auditory and visual, in order to prevent so distressing a situation leading to a sensory deprivation syndrome. ${ }^{9}$

In the later stages of rehabilitation other stressful situations will occur. In fact, throughout his life a spinal cord injured person must cope with many stressful situations in an able-bodied designed world, as well as with social attitudes of rejection and coldness. Appropriate coping strategies must be learned. ${ }^{10}$

The purpose of this paper is to describe our experience regarding the application of the relaxation techniques carried out in the Institut Guttmann. At first we included relaxation training during rehabilitation as a means of helping patients to cope with the stress that their newly acquired situation involves. Obviously, certain adaptations to the technique must be introduced to make it suitable for this type of patient. Our experience seems to prove that such adaptations, as well as the relaxation itself, have a positive influence on these patients. Learning and practising relaxation exercises pro- 
vide patients with an opportunity to come to terms with their new body image and the possibility of seeking more pleasing corporal sensations instead of painful ones.

\section{Methods}

\section{Acute stage}

In the acute stage the patient may present a high level of anxiety, agitation and sleeplessness. This anxiety is also experienced by the family. The patient feels that he has lost control both of his body and his surroundings and this may be associated with a strong feeling of helplessness.

In this period the patient is confined to bed, usually a kinetic one. The therapist uses a verbal relaxation technique to induce a state of relaxation.

Together with the therapist the patient is helped to carry out a corporal inventory which begins from the head region and includes both sensitive and non sensitive body regions. With regard to the non sensitive areas, the patient is instructed to form a mental representation of them, or, if he prefers, to touch or observe them if this is possible. $\mathrm{He}$ is then instructed to focus his attention on his breathing and imagine a particular scene or colour. Finally the therapist brings the relaxation session to a close and helps the patient to reconnect with his surroundings. To finalise the session the patient is invited to comment on the sensations experienced.

The patient is asked to practise this exercise at least once a day. Sometimes a close relative can be taught to assist the patient during the training period. If necessary an individually tailored tape can be prepared by the therapist.

One specific situation for using relaxation training may be in weaning the anxious patient from a ventilator. ${ }^{11}$

\section{Intermediate stage}

In the intermediate stage emotional distress related to the difficulties of coping with spinal cord injury and hospitalisation may be encountered. Muscular tension, anxiety and phobic attitudes usually accompany pain. The relaxation training will then be included as part of the overall psychological treatment. ${ }^{12}$

Relaxation training is carried out with the patient sitting in the wheelchair; however the patient may practise the exercise whilst lying in bed if he so prefers. Once the technique has been learnt, the main objective is to be able to produce this state of relaxation in any given situation of daily living.

During the initial sessions the therapist helps the patient to explore the most comfortable position for his arms, legs and head. In the course of the body inventory the wheelchair is included and reference is made to those areas of the body being supported by the wheelchair.

Training can be done individually or in a group setting. The training involves weekly sessions with the therapist, over a period of 6 to 8 weeks, and regular practice by the patient himself.

In the individual training a therapeutic modality based on progressive relaxation procedures developed by Bernstein and Borkovec $^{13}$ is adopted, in conjunction with the registration of electromyographic activity of the frontalis muscle. At the same time the patient is provided with an acoustic feedback of his muscular response in order to improve his learning capacity and to supply objective data about muscle relaxation.

When training is done in a group setting, progressive relaxation in combination with induction exercises are performed and the sharing of experiences and sensations becomes an important therapeutic aim. At the end of each session group discussion takes place.

\section{Pre discharge stage}

In this stage of his rehabilitation treatment, the patient has usually overcome the acute distress experienced in previous stages. He is now more capable of looking ahead to the future, and this, added to the imminent discharge from hospital, can cause certain problems to be reactivated. At this stage relaxation treatment is used to help overcome anxiety caused by social situations, to prepare the patient for hospital discharge and to provide emotional support. 
The relaxation technique used in this phase only differs from previous phases in that importance is placed on resocialisation. Individual training is done if considered to be necessary. At this stage inductions and visualisations directed at imagining situations such as the patient's future discharge from hospital can prove useful.

\section{Readmission}

Patients are readmitted to hospital for various reasons which can include repetitive medical complications or pain sequelae. In some cases we find that readmission has proved to be a frustrating experience. The psychological symptoms presented by these patients tend to be of a more structured nature than those encountered in patients from previous stages.

When the patient's psychological symptoms are due to a high level of tension, relaxation can be employed as a therapeutic strategy. The training here is individual and the technique followed is the same as that adopted in the intermediate stage. Emphasis is placed on relaxation learning and its application in everyday situations, with spe- cial attention being given to badly learned behavioural patterns.

A special situation is that of terminally ill patients whose spinal cord injury has resulted from cancer. ${ }^{14}$ In these patients the therapy employed is similar to that used in the acute stage, emphasis being placed on induction.

\section{Conclusion}

Relaxation techniques applied flexibly and adapted to the physical and emotional situation of the patient throughout the rehabilitation process, can prove useful for a great variety of patients.

Relaxation training applied in a rehabilitation setting is useful as multimodal adjunct therapy in treating emotional distress related to spinal cord injury onset and hospitalisation.

\section{Acknowledgements}

I wish to acknowledge the assistance of Miss M Mora and Miss J Salcedo in the early stages of this work, and also the contributions of Mrs Lesley Harvey and Miss R Bozal.

\section{References}

1 Stoyva JM (1978) Guidelines in the training of general relaxation. In: Basmajian JV ed. Biofeedback: Principles and Practice for Clinicians. The Williams \& Wilkins Company, Baltimore: 94.

2 Jacobson E (1938) Progressive Relaxation. University of Chicago Press.

3 Schultz JH (1932) El Entrenamiento Autógeno. 3rd ed. Científico-Médica, Barcelona.

4 Basmajian JV (1978) Biofeedback: Principles and Practice for Clinicians. The Williams \& Wilkins Company, Baltimore: 3 .

5 Valdes M, De Flores T (1985) Psicobiología del Estrés. Martínez Roca, Barcelona: 9-14.

6 Ost LG (1987) Applied relaxation: description of a coping technique and review of controlled studies Behav Res Ther 25(5): 397-409.

7 Corder BF, Whiteside R, Haizlip T (1986) Biofeedback, cognitive training and relaxation techniques as multimodal adjunct therapy for hospitalized adolescents: a pilot study. Adolescence 21(82): 339-346.

8 Trieschmann RB (1980) Spinal Cord Injuries: Psychological, Social and Vocational Adjustment. Pergamon Press, New York: 40.

9 Das S (1969) Some psychological problems of quadriplegics Med J Aust 2: 562-564.

10 Curcoll ML (1987) Estrés y lesión medular. Rev. ASPAYM (Valencia) 21: 1-5.

11 Costa F (1988) Biofeedback and progressive relaxation in weaning the anxious patient from the ventilator. Heart Lung 17(3): 299-301.

12 Mansfield J (1988) Enfoques multidisciplinarios de los pacientes con dolor crónico. En: Krueger DW, ed. Psicología de la Rehabilitación. Herder, Barcelona: 395.

13 Bernstein DA, Borkovec TD (1983) Entrenamiento en Relajación Progresiva. Desclee de Brouwer, S A Bilbao.

14 Fleming U (1985) Relaxation therapy for far-advanced cancer. Practitioner 229(1403): 471-475. 